\title{
FRONTAL MUCOCELE AND DIPLOPIA - A CASE REPORT
}

\author{
T.D. Thimmappa1, Ramesh S², Gangadhara K.S ${ }^{3}$, Hamsa Shetty ${ }^{4}$, Swathi C Prabhu ${ }^{5}$
}

\section{HOW TO CITE THIS ARTICLE:}

TD Thimmappa, Ramesh S, Gangadhara KS, Hamsa Shetty, Swathi C Prabhu. "Frontal mucocele and diplopia - a case Report". Journal of Evolution of Medical and Dental Sciences 2013; Vol2, Issue 38, September 23; Page: 7215-7220.

ABSTRACT: The paranasal sinus mucocele is an epithelized cystic lesion containing fluid and is characterized by non-neoplastic expansion of the paranasal sinuses due to its capacity to erode the overlying bone. Etiology of these lesions is still under debate. In this report, we describe a case of frontal mucocele associated with proptosis and diplopia. A 56 year old male patient was admitted to our hospital in the department of Otorhinolaryngology with chief complaints of left sided nasal obstruction, double vision, swelling in the left eye and headache, all since 3 months. CT scan of the paranasal sinuses revealed a left sided dense hypoechoic mass with destruction of floor of the frontal sinus with intra orbital extension. All other laboratory examinations were within physiological limits. The patient was treated surgically by external approach. An incision was put in the left supra-orbital region and a bone window was created to access the frontal sinus and the mass identified and excised in-toto. Dermal fat graft was harvested the thigh and grafted into the recess. Histopathological examination of the mass revealed the mass to be a mucocele.

KEY WORDS: frontal mucocele, proptosis, diplopia , paranasal sinuses, open sinus surgery.

INTRODUCTION: Mucocele of the paranasal sinuses is a local complication of chronic sinusitis.

The sinuses commonly affected are the frontal, ethmoidal, maxillary and sphenoidal sinuses, in that order of frequency. (1)

In rare cases, mucocele have extremely rare location: sphenoid sinus, orbito-ethmoid (Haller) cells, concha bullosa, and pneumatized uncinate process (2-5)

There are two schools of thought in the genesis of a mucocele (6):

i) Chronic obstruction to sinus ostium resulting in accumulation of secretions which slowly expand the sinus and destroy its bony walls.

ii) Cystic dilation of mucous glands of the sinus mucosa due to obstruction of its duct.

Most often patients present with a swelling in the superomedial quadrant of the orbit (90\%). Sometimes it presents as a cystic swelling in the forehead (10\%).

Patients present with headache, diplopia and proptosis which are usually mild. Radiographs of the frontal sinus reveal clouding of the sinus with loss of scalloped outline which is so typical of normal frontal sinus. Treatment is fronto-ethmoidectomy with free drainage of frontal sinus into the middle meatus.

CASE REPORT: A 56 year old male patient presented with the chief complaints of headache, left sided nose-block since 3 months and double vision since 2 months. Headache was insidious in onset and gradually progressive, more so in the left frontal region, aggravated during early morning hours and relieved on taking oral medication. It was not associated with nausea, vomiting, giddiness, loss of consciousness or convulsions. 
Patient later noticed a swelling in the inner side of the left upper orbit since 2 months, insidious in onset and gradually progressive. It was associated with double vision. Patient consulted an Opthalmologist and was referred to Otorhinolaryngology department.

There was no history of trauma, head injury, vomiting, loss of consciousness, or seizures. No previous history of hypertension, diabetes mellitus, tuberculosis or asthma. He did not recall any preceding discharge from the eyes or any past history of sinus surgery. Past history and family history revealed nothing significant.

On general physical examination, the patient was moderately built and nourished, conscious, co-operative, well oriented to time, place and person. Showed no signs of pallor, cyanosis, clubbing, lymphadenopathy or oedema.

Local examination of eyes revealed left axial proptosis with the left eye ball displaced inferiorly and laterally, non-tender and no restriction of eye movements. There was no h/o loss of vision or colour vision.

Right eye was essentially normal. Ear, Nose and Throat Examination: Anterior Rhinoscopy revealed mild deviated nasal septum to left side. Posterior rhinoscopy was normal.

PNS examination revealed tenderness over the left frontal sinus region with normal Maxillary and Ethmoid sinuses. Ear and throat examination was essentially normal. Vitals and other systemic examination were all within normal physiological limits.

Management: Basic lab investigations were within normal limits. However, CT scan of the PNS revealed a dense hypoechoic area in the left frontal sinus recess with destruction of the floor of the frontal sinus and intra orbital extension.

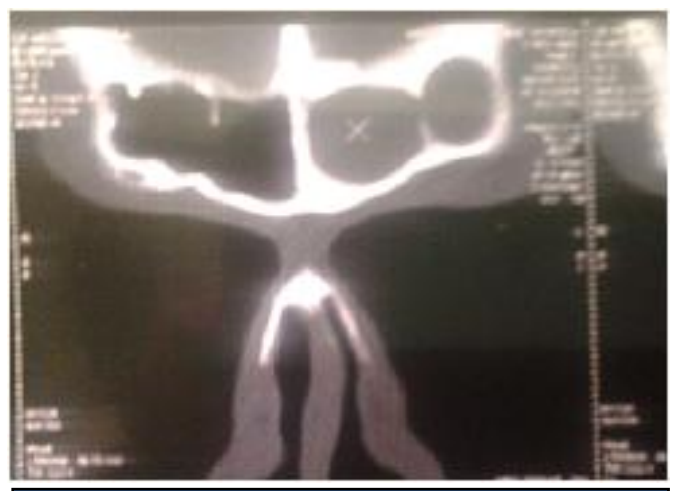

Fig 1: Dumbbell shaped frontal sinus with inter-sinus septum dividing the frontal sinus into 2 compartments.

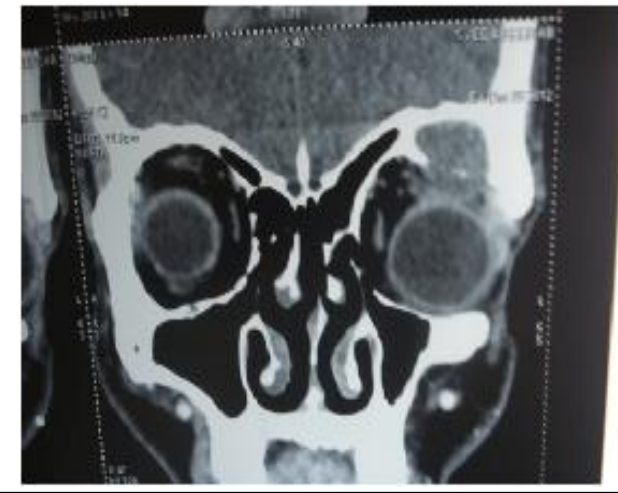

Fig 2: Lesion in the left frontal sinus with destruction of the floor of the sinus and herniation into left orbit. 


\section{CASE REPORT}

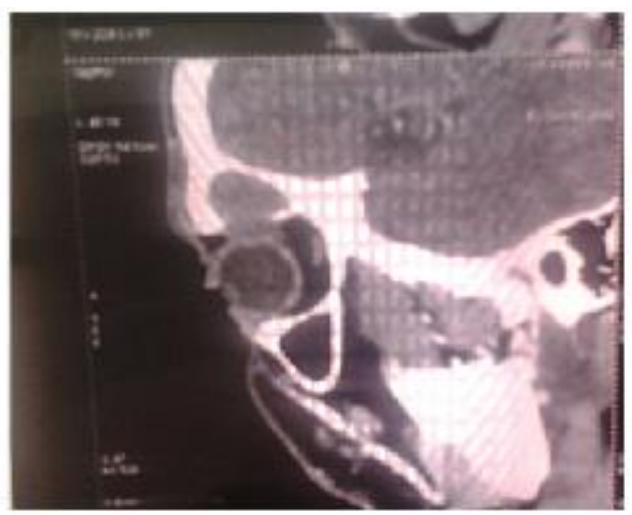

Fig 3: Sagittal section showing posterior table of the frontal sinus which is intact.

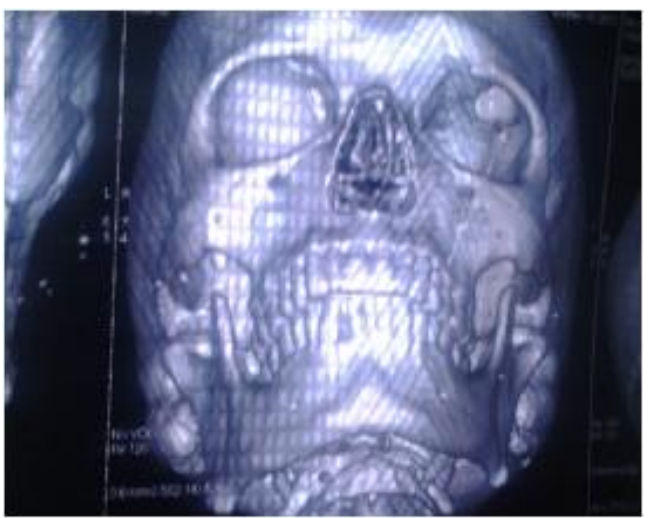

Fig 4: 3D image showing the defect in the floor of the frontal sinus.

Management: Surgery was the best option for the patient. Under GA an incision was taken in the left outer aspect of the supra-orbital region and the left supraorbital ring was exposed.

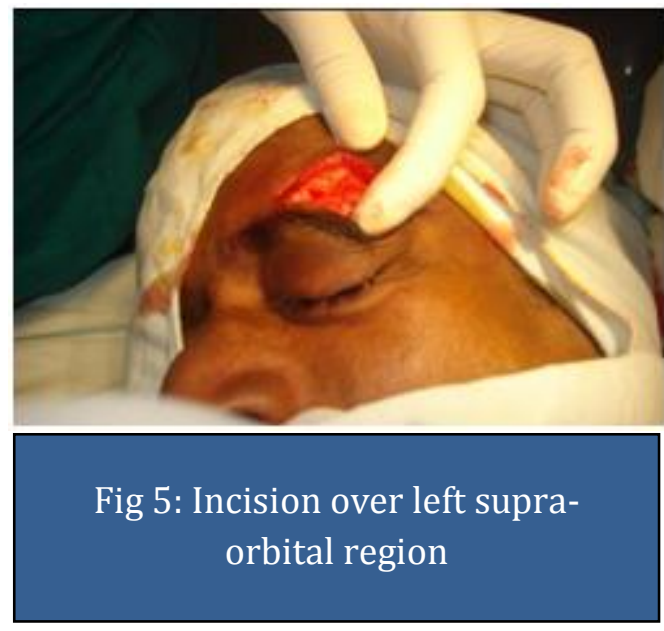

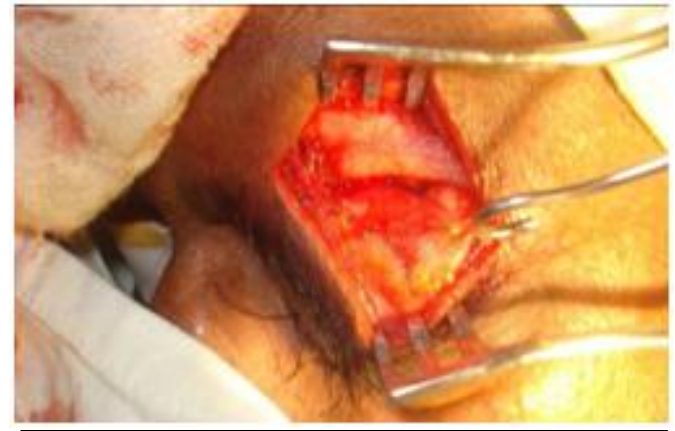

Fig 6: Bone and lesion is exposed. The frontal sinus recess with the mucocele is visualised

Next, the supraorbital ring was exposed and $1^{*} 2 \mathrm{~cm}$ bone window was created by cutting the rim- to have a direct vision of the frontal sinus.

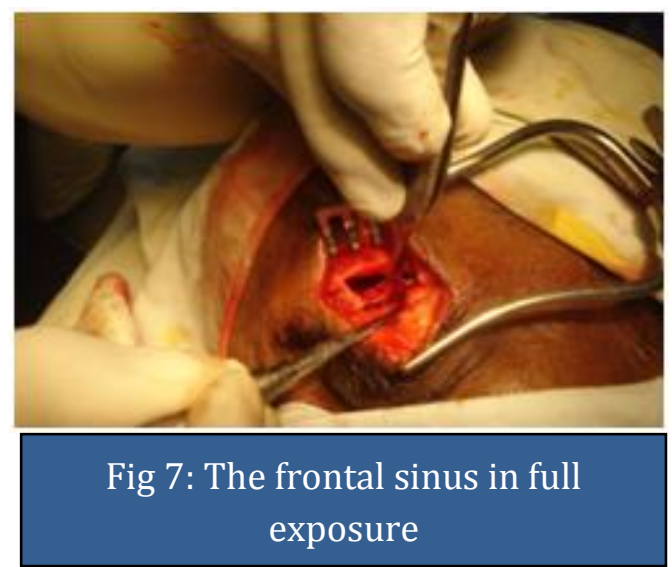




\section{CASE REPORT}

The posterior wall of the sinus was intact. (see below)

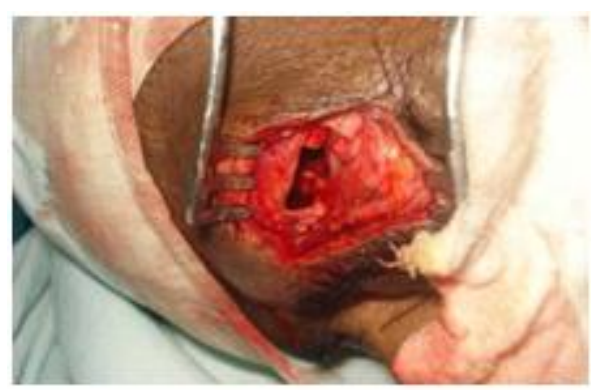

Fig 8: frontal sinus on full exposure

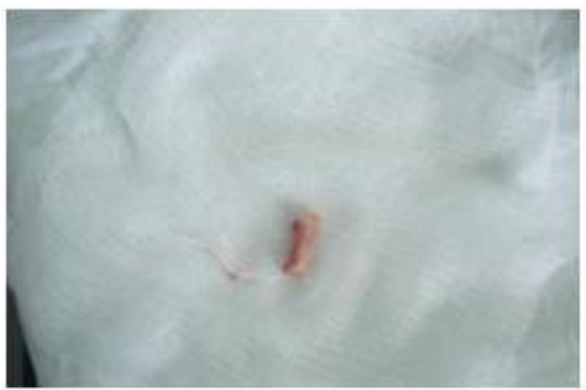

Fig 9: The bone plate removed to expose the frontal sinus.

The plate however was later replaced and intraosseous wiring done to fix it.

Dermal fat graft harvested from the left lateral wall of the thigh to fill the defect created by excising the mucocele. (See image below)

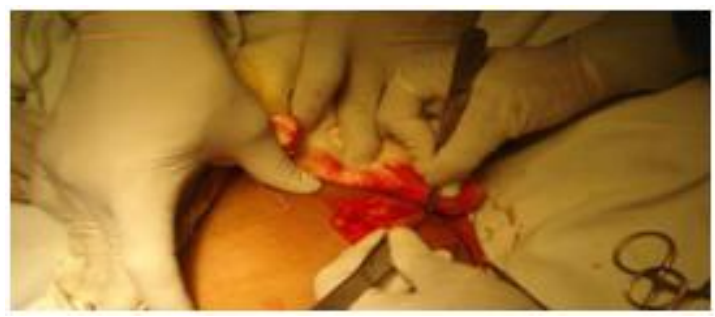

Fig 10: Dermal fat graft being taken from the lateral thigh

Next, wound was closed in layers and a subcutaneous suturing done to maintain the cosmetic appearance. Patient was advised to remove sutures after one week.

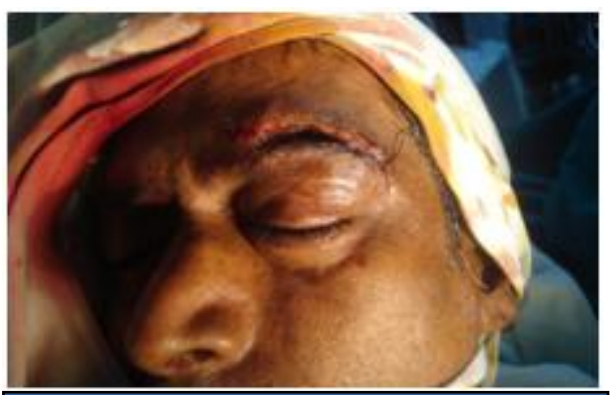

Fig 11: wound closed in layers 
Following a week after surgery, the patient experienced significant relief of symptoms. Headache completely resolved and the patient no more had double vision. Recovery was uneventful, patient was very much well since then.

Patient was reviewed after 6 months. The result was exceptional.

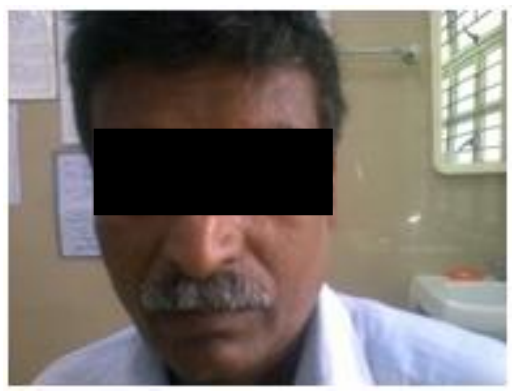

Fig 12: Follow up photograph showing

complete resolution of proptosis

DISCUSSION: $(7,8,9,10)$ : Sites of occurrence of mucoceles are the frontal, ethmoidal, maxillary and sphenoidal sinuses, in that order of frequency (7). The pathophysiology of fronto-ethmoid mucoceles has been lightened in experimental studies and by clinical observations that the trapped mucosa in the frontal and ethmoidal sinuses after obstruction of sinus ostia (8). They may occur at any age, but most of them are seen between the fourth and seventh decades. They are seen similarly at both sexes. Fronto-ethmoid mucoceles cause outward and downward displacement of the globe and are often associated with a palpable mass in the superonasal and medial canthal region. The expanding mass lesion may cause proptosis, restriction of eye movements, diplopia, visual loss, retroorbital pain or headache. The mucoceles of the frontal sinus may disrupt the medial canthal ligament and the orbital roof in which surgical interventions should include the reconstruction of these anatomic structures $(9,10)$. Many surgical approaches to frontal mucoceles have been defined but we preferred a external approach for the treatment of frontal mucocele (fig 1) as the sinus is dumbbell shaped with intersinus septum. Early diagnosis and appropriate management will have outstanding results. (fig 11)

\section{REFERENCES:}

1. Som PM, Brandwein M. Sinonasal cavities. Inflammatory disease, tumors, fractures, and postoperative findings. In: Som PM, Curtin HD, eds. Head and Neck Imaging, Volume 1, 3 edition. St. Louis: Mosby, 1996:126-85.

2. Razmpa E, Naghibzadeh B, Bagheri A, Sadeghi M, Khak M. The clinical manifestation, evaluation and surgical management of sphenoid sinus mucoceles: a case series and literature review. B-ENT 2011;7:87-90 PMid:218380912

3. Arrué P, Kany MT, Serrano E, Lacroix F, Percodani J, Yardeni E, et al. Mucoceles of the paranasal sinuses: uncommon location. J Laryngol Otol 1998; 112:840-4. http://dx.doi.org/10.1017/S0022215100141854, PMid:9876373

4. Yuca K, Kiris M, Kiroglu AF, Bayram I, Cenkaya H. A case of concha pyocele (concha bullosa mucocele) mimicking intranasal mass. B-ENT 2008; 4:25-7. PMid:18500018 
5. Burrows SA. Mucocele of a pneumatized uncinate process: first reported case. J Laryngol Otol 2011; 125: 635-7. http://dx.doi.org/10.1017/S0022215110002884, PMid:21269556

6. Dhingra Textbook of ENT.

7. Natvig K, Larsen T: Mucocele of the paranasal sinuses: retrospective clinical and histological study. J Laryngol Otol 1978, 92:1075-82.

8. Kennedy DW, Senior BA: Endoscopic sinus surgery. A review. Otolaryngol Clin North Am 1997, 30:313-330.

9. Ducic Y: Medial canthal ligament reattachment in skull base surgery and trauma. Laryngoscope 2001, 111:734-737.

10. Wetzel EK, Hollier LH, Calzada G, Manolidis S: Single stage management of complex frontoorbital mucoceles. J Craniofac Surg 2002, 13:739-745.

\section{AUTHORS:}

1. T.D. Thimmappa

2. Ramesh S.

3. Gangadhara K.S.

4. Hamsa Shetty

5. Swathi C Prabhu

\section{PARTICULARS OF CONTRIBUTORS:}

1. Associate Professor and HOD, Department of ENT, Shimoga Institute of Medical Sciences.

2. Assistant Professor, Department of ENT, Shimoga Institute of Medical Sciences.

3. Professor, Department of ENT and Dean, Shimoga Institute of Medical Sciences.

4. Junior Resident, Department of Otorhinolaryngology, Shimoga Institute of Medical Sciences.
5. House Surgeon, Department of Otorhinolaryngology, Shimoga Institute of Medical Sciences.

\section{NAME ADRRESS EMAIL ID OF THE CORRESPONDING AUTHOR:}

Dr. T.D. Thimmappa,

Associate Professor and HOD, ENT, Govt. McGann Teaching Hospital,

SIMS, Shimoga.

Email - drtdthimmappa@yahoo.com

Date of Submission: 29/08/2013.

Date of Peer Review: 30/08/2013.

Date of Acceptance: 03/09/2013.

Date of Publishing: 18/09/2013 